\title{
Negotiating Intimate and (A)sexual Stories
}

\author{
by Jo Woodiwiss
}

University of Huddersfield

Sociological Research Online, 20 (4), 1

$<\mathrm{http}: / /$ www.socresonline.org.uk/20/4/1.html>

DOI: $10.5153 /$ sro.3740

Received: 30 Nov 2014 | Accepted: 15 Jun 2015 | Published: 30 Nov 2015

\begin{abstract}
Drawing on a research project looking at women's engagement with therapeutic/self-help literature this paper uses the concept of narrative frameworks to explore women's negotiation of currently circulating stories of healthy womanhood, intimacy and sexuality. In a (western) world increasingly informed by therapeutic discourses, adult women are told they are entitled to happiness and success and failure to do so is seen to result from past (often traumatic) experiences which might or might not be remembered. Central to this construction of womanhood is what (drawing on Rich 1980) I have called 'compulsory sexuality' whereby the healthy adult woman is constructed as sexually knowledgeable, active and desirous. This not only puts pressure on all women to construct a (particular) active sexual self but helps to construct those who do not as problematic and directs them to seek both cause and solution in their damaged psychologies. One such cause is said to be childhood sexual abuse and the self-help literature aimed at survivors of such abuse encourages readers to use the idea(I) of an active sexual self as a measure of health, well-being and ultimately womanhood. In this paper I argue that contemporary narrative frameworks of healthy womanhood not only allows for women who are not, or do not wish to be, sexually active to be identified as problematic, but directs them to see themselves as damaged. In critiquing the sexual abuse recovery literature I also show how this can be used to create different a/sexual selves, albeit ones currently perceived to be 'damaged'.
\end{abstract}

Keywords: Intimacy, Sexuality, Childhood Sexual Abuse, Narratives, Self-Help, Therapy

1.1 From the myths and legends of earlier times to the survivor and confessional tales of the late twentieth and early twenty-first centuries we are the 'story-narrating animals ceaselessly creating stories and dwelling in our story telling societies'(Plummer online Manifesto for Stories 19/2/14). It is through our story telling that we not only make sense of ourselves and the world we live in but these stories or narrative frameworks also act as 'guides for living' (Woodiwiss 2009) and help us plan for the future. In telling our stories we do not simply slot ourselves into readymade narratives but draw on stories or narrative frameworks that are currently circulating and these are both culturally and historically specific (Bauman 2001; Jackson 1998; Lawler 2002; Plummer 1995, 2001; Woodiwiss 2009, 2014). Therefore, in telling our (and others') life stories we are not free to tell any story (Bauman 2001; Gergen 1994; Plummer 1995, 2001; Woodiwiss 2009) but must confine ourselves 'to toing and froing among the options on offer' (Bauman 2001:7). These options or narrative frameworks are increasingly informed by a therapeutic culture (Furedi 2004), which has seen an explosion of self-help literature and where greater and greater emphasis is placed on looking inward for possible causes of and solutions to difficulties we are encouraged to identify (Simonds 1996; Showalter 1997; Woodiwiss 2007, 2013). These difficulties or damage is often measured by the degree to which we adhere to or deviate from prescribed norms of behaviour including sexual behaviour. Whilst this culture is seen to have an authoritarian and coercive dimension (Furedi 2004; Lasch 1979; Sennett 1993) it also one in which we are 'educated in a therapeutic discourse of the emotions' which we can use 'to turn our own "cases" into stories, and become the authors of our own plot' (Rose 1989: 257) albeit within the constraints of currently circulating narrative frameworks. 
Not only do currently circulating stories and contemporary narrative frameworks encourage those unhappy or dissatisfied with their lives to construct themselves as damaged. They also promote ideals of healthy adulthood and encourage those who deviate from these ideals to construct themselves as problematic or damaged and in need of healing. One narrative which dominates the self-help literature and permeates many aspects of our everyday lives, is the 'harm story' (O'Dell 2003) of childhood sexual abuse (CSA). This narrative increasingly draws on psychological and therapeutic language and encourages those who are unhappy or dissatisfied to reinterpret their lives within a narrative framework of CSA, often with no concrete memories or knowledge of having been abused. It is a story retold in self-help literature, CSA recovery manuals and survivor auto/biographies. It also features in other cultural texts of the late twentieth and early twenty-first centuries from the problem pages of women's magazines to episodes of popular soaps, films and novels (Showalter 1997; Haaken 1998, 1999; Baker 2002). CSA, having entered the contemporary 'symptom pool' (Showalter 1997), has become a causal narrative, its plots and sub plots readily available and attractive to those who seek to make meaning of their lives, whether they have knowledge or memories of having been sexually abused or are simply unhappy or dissatisfied with their lives (Hacking 1995; Pendergrast 1999; Showalter 1997; Tavris 1992;

Woodiwiss 2009). It is a story in which all the ills experienced by women can be explained, not with reference to the external world, but through an examination of the internal world of their perceived damaged, and not yet healed, psychologies. Much of the recovery literature 'gives a clear story of what a good/normal woman should be' (Warner 1996:47), constructs women who deviate from this story as problematic (Tavris 1992; Woodiwiss $2009,2010)$ and constructs the victim of sexual abuse as both long suffering (Lamb 1999) and 'other' (O'Dell 2003; Haaken 1998; Reavey 2003). There is also a gendered dimension to the contemporary CSA narrative which is not restricted to unhappy or dissatisfied women. Deviation from prescribed norms of 'good' and 'normal' womanhood can also be seen as evidence of abuse and in turn used to reinforce prescribed norms of female behaviour, which includes behaviour related to sex and intimacy, within which women are encouraged to be sexually active and desirous, and identified as problematic or damaged if they are not. This harm story forms the basis of much of the CSA recovery literature but also shares with other elements of self-help and selfimprovement literature the message that the reader is both the cause of and solution to their difficulties.

The majority of victims of CSA are girls and the majority of readers of self-help literature aimed at victims, like readers of self-help literature generally (Simonds 1996), are women. In addition the research project on which this paper draws also focussed exclusively on women. Therefore, whilst recognising that boys/me can be victims of sexual abuse/read self-help literature, this paper will focus on women. In the first part of the paper I look briefly at sex manuals and self-help literature focussing on sex and intimacy before looking specifically at the CSA recovery literature (the majority of which includes sections on sex and intimacy) read by the women who participated in the study on which this paper draws. (Whilst some of this literature was written in the 1990s and early 2000s, it has been reprinted many times and is still currently read by victims and promoted by those working in the field of CSA recovery). I will then discuss how participants engaged with this literature to construct their own sexual selves. Whilst not all those who identified themselves as victims of sexual abuse believed they had a problematic relationship with sex and intimacy, a narrative framework centred on CSA is one that identifies both too much or too little sex as problematic. It is also a narrative that offers little chance to create an asexual self unless it is one that is damaged and in need of healing - in other words it recognises asexuality only as a temporary (and damaged) identification.

\section{Contemporary stories of sex and intimacy}

2.1 The CSA recovery literature and popular narratives of CSA are based on the (equally flawed) oppositional constructions of childhood as a time of sexual innocence and adulthood as a time of sexual desire, knowledge and activity (Woodiwiss 2014). CSA is thought to disrupt both these states. Therefore sexual feelings, activity or knowledge in childhood and/or their lack in adulthood can be used as evidence of this disruption and therefore also of CSA (Woodiwiss 2014). Whilst the CSA recovery literature constructs the healthy adult woman as sexually knowledgeable, desirous and active, it is not alone in promoting such messages. These constructions are reinforced through a variety of cultural texts through which we are bombarded with the notion that we should be, and should want to be, sexually knowledgeable, active and desirous - but to just the right degree. Too much sex is constructed as just as problematic as not enough (Woodiwiss 2014).

2.2 When the magazine Cosmopolitan turned 40 (Feb 20th 2012) the editor, Louise Court, suggested in an interview that 'Most people prize having a happy relationship as one of the most important things in their lives, and one of the keys is having a happy sex life'. She went on to say, perhaps not surprisingly, that in the twentyfirst century sex still sells. But not only does sex sell, sex is itself a big seller. There is now a proliferation of advice or self-help manuals for those wishing or needing to improve what and how they 'do' sex, with over 8,000 
sex guides listed on Amazon.co.uk. These include titles such as: The Good Sex Guide: The Illustrated Guide to Enhance Your Love-making (Dr. David Delvin 1993), Fabulous Foreplay: The Sex Doctor's Guide to Teasing and Pleasing Your Lover (Dr. Pam Spurr 2007) and Sizzling Sex: The Sex Doctor's 250 Hottest Tips, Tricks and Techniques (Dr Pam Spurr 2008). Often we do not need to read beyond the title to know what the message is. There are also texts for those who want to get in touch with their 'wicked' side or engage in something 'naughty' such as Sinful Sex: The Uninhibited Guide to Erotic Pleasure(Dr. Pam Spurr 2002) and The Naughtiest Sex Guide (with Bonus Erotica) (Sparx 2011). However, as The Good Girl's Guide To Bad Girl Sex(Keesling 2009) suggests, it is possible (and possibly important) to maintain a 'good girl' identity whilst engaging in 'bad girl' sex. Even the relationship guidance service Relate offers advice on sex although, as their title The Relate Guide To Sex In Loving Relationships (Litvinoff 2001) suggests, the appropriate place to have sex is in 'a loving relationship'. There are also titles for those with a bit more to learn, or who think they have a bit more to learn, such as: Good Sex: A Woman's Guide to Losing Inhibition(Kane 2006) and Sexually Shy: The Inhibited Woman's Guide to Good Sex (Kane 2009).

2.3 Not only do these texts promise advice but, with titles such as The sex starved marriage (Davis 2003) these manuals also convey a warning or note of caution. The majority of contemporary sex manuals argue that 'sex is integral to the maintenance of a long term relationship' (Gupta and Cacchioni 2013:447). Sex, the writers tell us, is important for our personal well being as well as our relationships and the avoidance of sex can not only take a heavy toll on our relationships but can also 'help us grow as people and as partners' (Comfort and Quilliam 2009:9). There is also an increasing tendency for these sex manuals to be written by doctors which conveys, or is intended to convey, a degree of (medical?) expertise or authority. In keeping with some of the above texts, whilst not a sex-manual, the Fifty Shades trilogy has not only been extremely popular but has been 'capitalized on by some sex shops and sex toy retailers through the creation of product ranges and in-store classes' ... whereby readers can purchase 'particular products and sexual knowledges in order to convert their Fifty Shades sexual fantasies into their own erotic realities' (Martin 2013:982). A 'female brand' of BDSM (Martin 2013) might have been made popular by Fifty Shades but, it seems, women still need to learn how to do it.

2.4 Whether or not we actively seek out the information in these manuals the messages they contain also permeate more everyday cultural texts such as films, magazines and television and radio programmes. What these texts tell us is that sex is important, sex is fun and sex is a bit naughty. Sex is also something we should all want, should all have and should all enjoy. There is also the suggestion that most of us don't know quite how to do it or at least how to do it right. It is no longer enough to 'simply have sex, but there is also pressure for the sex to be immensely enjoyable' (Przybylo 2011: 448). A message mirrored in television programmes such asThe Sex Inspectors in which the presenters not only offer 'a "right" way to have sex, which necessarily involves instruction, goals and evaluation' (Harvey and Gill 2011: [2]).) but also, like broader self-help literature, speak to an individualising narrative in which failure to enjoy a satisfactory sexual encounter is said to be the result of laziness, lack of the right products or not trying hard enough (Harvey and Gill 2011) rather than the realities or circumstances of one's life. Like the more general self-help literature, these broader messages around sex are also gendered and, as Gavey suggests, it is 'no longer simply the case that women are expected to have sex with men when they don't want to, but within certain parameters they are expected to want it most of the time and the problem is they don't (seem to)' (Gavey 2005: 111). Whilst asexuality is becoming recognised and available as an identity (seeCarrigan 2011; Scherrer 2008) the overwhelming message in this literature (and the CSA recovery literature) is that to be asexual is to be pathological or damaged in some way and therefore not functioning 'normally'. Indeed asexuality, or lack of sexual desire, is in itself seen by some as a symptom of sexual abuse which victims need to heal, itself measured by their sexual desire and activity (see below).

\section{Sex and intimacy in the CSA Recovery literature}

3.1 Women do not have to engage directly with literature aimed specifically at sex and relationships to read about the importance attached to sex/uality for healthy womanhood as these messages are also promoted in other self-help literature including that aimed at self identified victims of CSA. Whether they come to the CSA recovery literature through reading more general self-help / self-improvement literature, through involvement with counselling or therapy, or through reading literature specifically aimed at sex and intimacy, readers of the recovery literature are presented with sections on sex, intimacy and relationships. These sections, like those addressing other aspects of readers' lives, encourage the reader to identify problems or difficulties, often through a series of checklists with 'symptoms' ranging from having too much or not enough sex through to problems with being intimate or failure to reach orgasm. These checklists operate on a number of levels: they identify the reader or victim as the cause of these 'symptoms'; they promote particular ways of being; they help identify evidence and reinforce the victim narrative (which might be fragile for those relying on alternative memories); they identify and reinforce the need for healing and recovery; they reinforce the importance attached to sex and intimacy; they 
promise a way to achieve this (and thereby conform to dominant constructions of 'normal' healthy adult womanhood). One of the most popular texts (which has been reprinted many times) The courage to heal (Bass and Davis 1988 2008), which was also read by the majority of the women in this study, included such questions as:

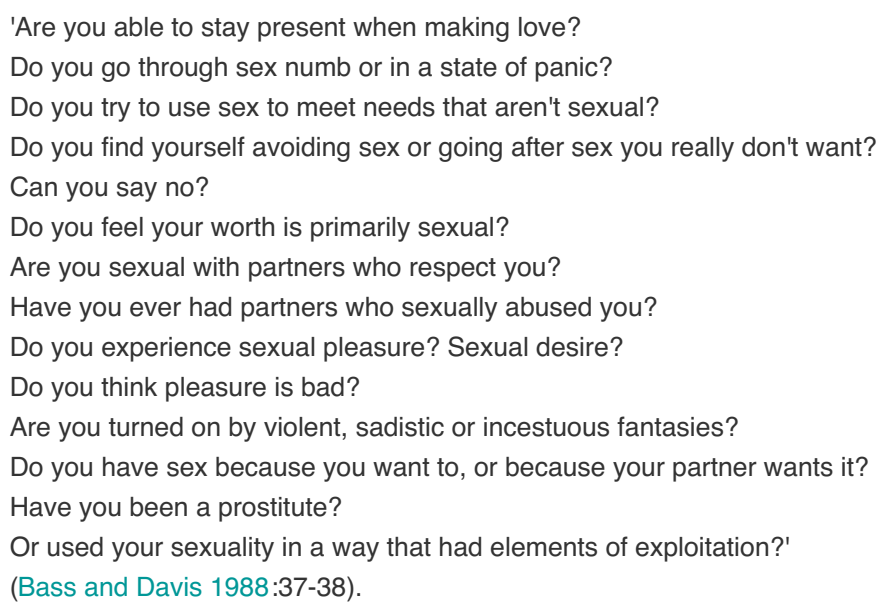

Other recovery texts, including those read by the participants, such as Secret survivors (Blume 1990) and Rescuing the 'inner child': therapy for adults sexually abused as childrenby (Parks 1990) identified a similar range of symptoms. Some of the CSA recovery literature does acknowledge that in contemporary western society women are bombarded with cultural messages which mean that sex can be problematic and complex for women (Bass and Davis 1988) and that many of the 'symptoms' are associated with women generally Showalter 1997; Haaken 1998,1999; Reavey 2003). However, within the recovery literature this is dismissed with sexual difficulties said to be compounded for victims of CSA. Victims' reactions to having been abused, rather than the cultural messages around sex, are constructed as problematic. Parks (1990), for example, identifies a number of 'problematic sexual experiences' for sexual abuse victims ranging from too much or too little interest in (penetrative) sex to being unable to have an orgasm. Dinsmore also suggests there are 'several ways a survivor may relate sexually' (Dinsmore 1991:92) which she identifies as both unhealthy and problematic:

She may be asexual, having no sexual contact with anyone... she may be very sexual with numerous partners but not feel emotional or physical pleasure. She may feel obligated to be sexual in a primary committed relationship but not feel any pleasure (Dinsmore 1991:92-93).

3.3 Readers are told there are wrong, and by implication right, ways to relate sexually (Kitzinger 1993; Haaken 1999; Woodiwiss 2009), at a time when the margins for women between being too sexual and not sexual enough have narrowed to produce 'an even more slippery tight rope for women to walk' (Jackson and Scott 2004:248). The literature promises a route to a happy and successful sex-life but it does so by shifting attention away from the external world and cultural messages and towards the internal world and psychology of the survivor, whilst at the same time drawing on these messages to suggest what is appropriate.

3.4 Whilst I'm not suggesting there is necessarily something wrong with telling us how to enjoy sex, there is a problem with the suggestion that we should be doing it, and enjoy doing it and, by implication, there is something wrong with us if we aren't or don't (or aren't in the right way or to the right degree). Whilst this permeates all aspects of our lives nowhere is this clearer than in the sexual abuse recovery literature - which is aimed at self-identified victims of CSA including those who believe their lives show evidence of CSA. This includes those who do not enjoy an active and fulfilling sex life, as this is seen to be one of the symptoms of having been sexually abused (Woodiwiss 2010). The CSA recovery literature is largely aimed at and read by women. Whilst the failure to have great sex is identified by The Sex Inspectors as risking the breakdown of a relationship, in the CSA recovery literature such failure (and indeed the 'failure' to engage in any kind of sex or too much sex) is seen as evidence of psychological damage resulting from a traumatic experience - within which failure to heal also risks the breakdown of relationships.

3.5 Readers are encouraged to conform to an active and desirous sexual self and 'failure' is seen as problematic and potentially as evidence of psychological damage. Having identified themselves as problematic readers can find advice for improving their sexual and intimate lives in the pages of the sexual abuse recovery literature as well as in the many sex and relationship guides currently available. However, for some it is the identification of a problematic relationship with sex through reading sex and relationship guides that leads them 
to the sexual abuse recovery literature (Woodiwiss 2009). This literature, reflected in popular understandings, constructs victims of CSA as 'sexually damaged' to the extent that a measure of recovery from sexual abuse, and a goal to be aimed at even in the face of a lack of desire, is seen as an active sexuality, and lack of an active sexuality is seen as both evidence of sexual abuse and a failure to recover from that abuse. Ideas about the importance, and degree, of sex and desire is reflected in other cultural texts as we are all expected to engage in just the right amount of sex and for just the right reasons.

\section{The research: methods and participants}

4.1 The remainder of this paper draws on the findings from an Economic and Social Research Council funded research project exploring women's engagement with CSA recovery literature. Sixteen women participated in the research of whom the majority had no recall memories or concrete knowledge of having been sexually abused. Five identified themselves as having continuous, concrete memories of CSA, six believed they had recovered memories of CSA (with all but one of these based entirely on 'alternative memories' - or perceived 'symptoms' redefined as 'memories' - see Woodiwiss 2010 for fuller discussion of 'alternative memories'), and five believed they had recovered false memories of CSA and were victims of false memory syndrome (FMS). Of the five who believed they had recovered false memories, three did not reject entirely the idea that they had been sexually abused in childhood, only that the perpetrators were their fathers. However, the research was not concerned with establishing the 'truth' or 'falsity' of women's claims but took as its starting point that women's memories and the narratives they told were 'true' to them, whilst recognising that, like all of us, they are constrained by the stories that can be told (Bauman 2001; Gergen 1994; Plummer 1995, 2001; Woodiwiss 2009 , 2014).

4.2 The research was conducted, in accordance with the ethical guidelines of the British Sociological Association, in the United Kingdom where all the participants were living at the time. The women were contacted through an article describing the research and calling for participants which appeared in the newsletter of two organisations: one supporting self identified victims of CSA, and one supporting those who identified as victims of false memory syndrome. The latter resulted in few responses and the organisation sent an additional letter to female members on my behalf. All the names in this paper are pseudonyms. The women's experiences, whether of 'healing' and 'recovery' or recovering false memories, occurred in Britain but they were not all British. Ten women were white British, two were British Asian, two were white European, one was non European of mixed heritage, and one who identified as 'other'. The majority were in their thirties (seven) or forties (six) with one women in her late fifties and two in their early sixties. Eleven identified themselves as heterosexual, two as heterosexual with some bisexuality, one as bisexual, one as lesbian and one as 'gone off men'.

4.3 The aim of this research was to explore women's engagement with the CSA recovery literature in the process of making sense of their lives, (re)constructing their life stories, and planning for a brighter future. The research was conducted within a feminist social constructionist framework. The intention was not to focus on women's experiences or memories of CSA (and indeed the majority of the women had no concrete memories of abuse). I therefore chose a two-stage approach with a questionnaire followed by either an interview or written account. The questionnaire was designed to establish some background information including, if known, women's age, sexuality, the time and place they believed the abuse took place, who had abused them, and what self-help and recovery literature they had engaged with. This enabled women's abuse histories to be taken as given, leaving the second stage to focus on women's engagement with the process of 'healing' and 'recovery'. In this stage participants were given the choice of being interviewed (11) or providing a written account (5) (based on the same semi structured interview questions). The interview schedule was designed to encourage a conversational style in which women were able to talk more freely than if responding to rigid questions (Burgess 1984; Whyte 1982), and allowed them to determine the nature and depth of their responses. However, I was also mindful with this style of interviewing, particularly as this format is similar to techniques used in counselling (Egan 1982; Whyte 1982), of the potential for me to exploit my interviewees and the need to guard against this where possible (Kirkwood 1993).

4.4 The interviews lasted between two and six hours (of which one went over two sessions) with the majority conducted in participants' own homes but with one conducted at a University office. They were all conducted by the author, tape-recorded, and later transcribed. The written accounts were conducted at a time and place of the participants choosing and posted to the researcher. Once the interview transcripts and written accounts were collected they were subjected to thematic analysis. All the transcripts and written accounts were read multiple times to identify principle themes and particular areas of interest. A further re-reading and revision of the themes resulted in a number of the themes being subsumed into larger themes or categories. This reflexive process allowed me to develop themes by immersing myself in the data through reading and re-reading the material 
(Braun and Clarke 2006) rather than by indexing the text with coding software. This produced a number of overarching categories or mega themes within which sex and intimacy featured as a sub theme and it is that material relating to sex and intimacy that is the subject of this paper.

\section{Stories of / identifying sexual problems}

5.1 All the participants, whether they had continuous or 'recovered' memories, drew on a contemporary narrative framework of CSA in the process of making sense of their lives and constructing their own life stories, even if some later rejected their story or elements of it. In doing so, they did not adopt readymade scripts but made use of a narrative framework in which they were able to draw on different elements depending on their experiences, their memories, what they wanted to make sense of in the past and/or the present, and what they wanted for the future. Some were trying to make sense of remembered childhood abuse (including sexual abuse), others to make sense of sexual feelings in childhood, and others to make sense of adult experiences or unhappiness. For some this included a lack of sexual desire whilst others were concerned that their sexual activities and intimate relationships were problematic. The only 'evidence' some participants had of CSA was 'a problematic relationship with sex and intimacy'. As one participant reflected on reading Blume's Secret survivors (1990):

'When I read it I still didn't have any memories then but I went yes, I mean if that's what happened that would explain it so much'. (Beccy)

Sex is seen as marking the boundary between childhood and adulthood and therefore sexual abuse is seen as disrupting this boundary and therefore also the normal development into adulthood. With the marker between childhood and adulthood identified as sex (knowledge, activity and desire) then it is sex, and the related concept of intimacy, which are seen as most likely, or even inevitably, to be damaged. Not only is CSA often portrayed as a 'profoundly deforming experience' (Contratto and Gutfreund 1996) and its victims as 'not well adapted to adult life' (Herman 1992:110) but this damage is often constructed in sexual terms. Much of the CSA recovery literature encourages the reader to connect the past with the present, and view the present through the lens of the past (Gavey 2003). When that past is sexually abusive it is seen as central in the development of adult sexual 'problems' (Kitzinger 1993; Hacking 1995; O'Dell 2003; Reavey 2003). The CSA recovery literature, like other elements of therapeutic and self-help culture, also has a tendency to locate both CSA and female sexuality within a liberal discourse of 'choices' (Kitzinger 1993; Reavey 2003) thereby making it easier to identify (sexual) difficulties experienced by survivors as individual (internal) problems, and to render invisible or irrelevant the wider power dynamics and imbalances that inform these 'choices' (Gavey 1993; O'Dell 1997; Haaken 1998, 1999; Reavey and Warner 2001; Woodiwiss 2009). Sexual difficulties, including lack of interest, was a theme which permeated many of the participants' stories, although for most it gained prominence only occasionally. However, where the women did engage with discourses around sex and sexuality this was complex and reflected not only their need to make sense of their lives up to the present but also to negotiate a future which they may or may not wish to include sexual relationships.

\section{Learning (how) to be sexual}

5.3 The majority of the CSA recovery literature is not specifically heterosexual. Many advice manuals do not mention the gender of a woman's partner and some include a section on lesbian sex. Instead as Kitzinger argues (1993) they present a gender-neutral analysis of sexual violence which fails to acknowledge different sociopolitical and personal meanings between lesbian sex and sex with men and assume there is nothing about CSA that might have implications for women's relationships with men. The CSA recovery literature does recognise women's vulnerabilities but usually within a context that promotes the idea of liberation, choice and women's agency (Kitzinger 1993; Reavey 2003). Reinforcing rather than challenging cultural pressures on women to behave as sexual beings, much of this literature holds up the achievement of an intimate sexuality as a measure of women's recovery from CSA and therefore as a goal to be achieved or aimed for. In doing so it also reinforces the idea of asexuality as a problematic or pathological identity which needs to be fixed. There is, as Bass and Davies cajole, 'no finish, no goal except intimacy, honesty and pleasure' (Bass and Davis 1988:248) but within the context of healing and recovery the survivor is held responsible if a sexual relationship does not measure up.

5.4 Although sexual activity and desire were identified as a measure of well-being and a goal to be aimed at, the reader who was not sexually active or desirous was told she did not need to fully develop her sexuality immediately. Instead she is told to 'allow yourself the freedom to do only what feels good' (Bass and Davis 
1988:243) but also that some day they would be ready and 'can't simply say no every time'ßass and Davis 1988:250). A woman's need or wish to say no to sex is defined in the recovery literature as a measure of her ongoing need to heal. In what is claimed to be a liberating approach which helps to make sex more accessible, Bass and Davies discourage readers (victims) from waiting until they are ready or sexually desirous. Instead they encourage readers to begin sexual activity 'even if you're not feeling physical longing, emotional excitement or desire of any kind' (Bass and Davis 1988:254). To help them get started women are encouraged to use a vibrator, especially if they have not used one before and 'try a little teenage sex' (Bass and Davis 1988:250). No longer told they 'owe it to their man' women are now told they 'owe it to themselves'. Asexuality, it seems, is only a temporary option and only available to the particularly damaged or vulnerable. Readers who learnt through unwanted sexual experiences in childhood that they don't like or want sex, are encouraged to write to their 'inner child' (the child self said to be trapped at the time of the sexual abuse) telling them 'what the correct attitude is and how to adopt it' including such advice as 'sex is good. It really is' (Parks 1990:144-145). Failure on the part of the reader to recognise the 'goodness' of sex is itself evidence of abuse and/or a lack of healing.

In both professional and popular narratives, talk about sexually abused women is often based on an assumption that those who have not been sexually abused progress along a 'normal' developmental path to a healthy sexuality. In contrast, for those who are sexually abused in childhood this developmental path is said to have been blocked and they are said to fail to progress to a normal healthy sexual self. They are, Parks suggests:

'Women who cannot be penetrated, women who cannot have an orgasm, women who are not interested in sex at all and women who are not interested in men at all... also women who have a great deal of sex without physical satisfaction' (Parks 1990:143).

Past abuse can therefore not only be used to reinforce a normative sexuality but can also be used to explain a failure to adhere to such a normative sexuality (Reavey 2003). In a somewhat circular argument, failure to adhere to a normative sexuality can also be seen as evidence of past sexual abuse. This pervasive view informed the narratives told by participants in this study:

'You've got a reason anyway why you're blocked, maybe if you weren't blocked you wouldn't be a virgin you would be enjoying a sex life'. (Tracey)

5.7 Bombarded with messages around being sexually active and told there is something wrong if they are not, whilst problematic, can at the same time be reassuring for some women. It offers them an explanation or cause for their lack of interest or desire (which they are told is problematic and unhealthy), and offers the possibility of addressing this problem and developing a happy and fulfilling sex life - something they felt they should achieve even if they didn't feel they wanted to. However, in order to do so readers did have to construct themselves as the problem, by identifying a 'block' or area to be worked on:

'So the self-help books really helped with that because they show you what, people who have been sexually abused, these could be the symptoms and what you could do'. (Tracey)

5.8 It may be that, out of the currently available options, the CSA recovery literature offered readers the best way to achieve their aims, if only because it gave them some time within their (sexual) relationships to discover what they wanted. As Carrigan suggests of those seeking to explain an asexual identity

'Depending on their placement within society, individuals have access to differing material and cultural resources and this conditions the potential explanations available to them' (Carrigan 2011:473).

5.9 Whilst for those in Carrigan's study the available explanations were often presented in terms of an assumed pathology, the women who participated in my own study were presented with explanations which constructed them as 'damaged'. However this latter construction was seen as temporary, and through healing they would become sexual beings.

5.10 When they engaged with the CSA recovery literature women were often tapping into ideas already familiar to them. Some used this literature to explain or excuse a lack of interest in sex whilst for others it was the amount of sexual activity they engaged in or their reasons for doing so that was in need of explanation. As the healthy adult woman is expected to desire the right amount of sex and for the right reasons, readers of the CSA recovery literature were told that those who engage in too much sexual activity are unhealthy, or psychologically damaged, and said to confuse sex and love. There may be: 
women who have orgasms but cannot form a loving relationship, and women who think they must have sex with every person they go out with in an effort to feel loved and important' (Parks 1990:143).

5.11 As this indicates, readers were not only encouraged to identify problems within their intimate relationships but to locate the cause of these problems with themselves. This narrative, which renders their partners invisible, was taken up by Jenny and Sarah:

'I hadn't had a boyfriend for a year and fell obsessively in love over and over again, a kind of love and sex addiction with no real intimacy'. (Jenny)

'Then I was having a rough time in a relationship and the only way I could relate to anything at the time was on a sexual basis'. (Sarah)

5.12 Both Jenny and Sarah were involved in relationships, or types of relationships, they were unhappy with. They also accepted they were responsible and traced the cause back to childhood experiences:

'At the same time a longing for love and attention got mixed up with sex and led me into repetitive short-term affairs that never developed into the relationship I craved'. (Jenny)

5.13 The CSA recovery literature offered readers an explanation for their unsatisfactory relationships, together with the possibility of finding or building the kind of relationships they wanted. However, in holding them responsible, removing their partners from responsibility, and failing to recognise the external influences on those relationships the literature also risked putting readers under additional pressure. Not only were they encouraged, or cajoled, to engage in sexual relationships they might not desire, but held responsible for making sure those relationships were healthy and fulfilling. Significantly, it was not only victims or readers of the recovery literature who drew on damage narratives of CSA or dominant messages such as those promoted by sex experts or The Sex Inspectors. This literature could also be used by others to apply pressure to readers or victims to conform to an ideal of an active sexuality or participate in particular types of sexual activity. For Fiona, it was her boyfriend who introduced the idea that she was sexually damaged:

\footnotetext{
'He feels as if it's a barrier and as if it's like a thing that's broken and it's unfortunate that that thing doesn't work properly. That our sexual intimacy, my sexuality is kind of damaged. It's not whole it's been damaged by what happened'. (Fiona)
}

and in doing so he was also able to introduce the possibility that she needed to learn (from him) how to be sexually active in a particular way and to a particular degree. In accepting her damaged status, Fiona was left with little option than to acquiesce to her partners' wishes, which they both understood to be beneficial to Fiona. Whilst not suggesting that Fiona's partner sexually abused her or coerced her into having sex she did not want, this literature does present a framework within which (potentially) abusive partners could not only do both, but justify those actions as contributing to the victim's recovery process. Frances also believed that CSA was the cause of a list of sexual problems but again she is the only one whose responsibility for these sexual difficulties is visible in her story:

'It made me more precocious, more insular, promiscuous, frigid... unloving and unloved'. (Frances)

5.14 The idea that childhood experiences had damaged her ability to be sexual was also adhered to by Tracey. Her first experience of therapy was related to what she identified as a sexual problem and for her a link with CSA was clear:

'The first therapy I went to was a couple of years ago before I met David and erm that was talking to someone about sexuality because I wasn't comfortable with that as well, sex and it just wasn't... you know if I wanted to lose my virginity I didn't feel comfortable because I had been tampered with'. (Tracey)

5.15 The literature, having alerted the reader to possible difficulties, offered them a way to become fully functioning sexual beings. This might encourage some to look for examples of sexual problems in their own lives, or redefine as problematic, experiences they were previously happy or content with. However, for others it helped explain symptoms they already identified as problematic or wanted to address:

'They said in the book that you know, sex is not an enjoyable experience for someone who has been abused in that way at an early age and they don't have, orgasmic, you get an orgasm from yourself but you don't get it so much from someone else. And I had that you know'. (Tracey)

5.16 Tracey was unhappy with her inability to be sexual and for her the recovery literature was helpful:

'There was a book on sexual, sexual genitals and how to relax them and how to feel safe with them. I used them you 
know, relaxing the abdominal muscles and diaphragm and just doing breathing exercises and just you know, walking naked in the flat and just feeling comfortable. Looking at yourself in the mirror and going, you're beautiful and just looking at yourself'. (Tracey)

5.17 Whereas Tracey entered adulthood with concrete memories of having been sexually abused as a child and was clear that this was a cause of her sexual difficulties, others were, initially, less clear as to why they were unable to conform to an active sexuality. For Beccy, it was a sexual problem which first led her into therapy and whilst she came to believe this was 'evidence' of a history of CSA this was not always the case:

'I didn't know the source of the problem then I just had a problem with sex and I didn't know where it came from, I didn't have a clue'. (Beccy)

5.18 Beccy came to identify herself as a victim of CSA through identifying sexual difficulties in her adult life which she connected to CSA. However, the only evidence Beccy had of having been abused were these difficulties and without such a view of sexuality she would not have been able to construct a narrative of CSA or herself as a victim.

5.19 The CSA recovery literature not only promoted an active and fulfilled sexuality as a measure of recovery and a goal to be achieved, it also made it clear that there are right and wrong ways, or reasons, to be sexually active. Whilst this message could be problematic for readers, it was a message that some participants were able to resist. Jay had been sexually and psychologically abused throughout her childhood by numerous people and had learnt that sex could be used as a tool to help her negotiate different aspects of her life:

'I just found that if Stewart was in the mood I'd have sex just to placate him... I just found I was having sex for all the wrong reasons... I realise I use sex as a tool erm, it's just very rarely I'll have sex because I feel affectionate and loving and just want to make love (Jay).

5.20 The recovery literature made it clear that this was a 'wrong' reason for engaging in sexual activity and that her attitude to sex could be considered problematic, but Jay recognised that this would create additional problems for her and was ultimately able to reject the construction of herself as the problem:

It made me really concerned about it for a while and now I've decided that basically if that's how I am, that's how I am and I just live with it rather than worrying about it... and creating more problems'. (Jay)

5.21 Jay was not the only one to resist the lessons of the recovery literature and recognise other influences beyond sexual abuse on their adult lives. Emma believed it was the context in which her abuse occurred as much as the abuse itself:

'I am single and have been for a long time and I can't imagine that I'll ever be happily married. I think that's because my parents' marriage was a sham'. (Emma)

5.22 However, in doing so she did also take on board some of the messages promoted in the recovery literature and believed she was 'emotionally retarded when it comes to relationships with the opposite sex' (Emma).

\section{Stories of intimacy and resistance}

5.23 Although, as Kitzinger (1993) points out, much of the CSA recovery literature has sections on sex, they do not have a section on how to maintain celibacy in our sex-obsessed culture. Celibacy or asexuality are not readily available to those reading the CSA recovery literature. Instead, the reader is told that 'Sexual healing is a beautiful gift a survivor can give herself' (Maltz and Holman 1986:138), or event that they must make an 'active attempt to accept sexuality as a good and natural thing - which it is!' (Parks 1990:148). Whilst readers were bombarded with such messages through the CSA recovery literature and other cultural texts, not all accepted sexuality as a 'good and natural thing' and some wished to negotiate relationships that did not involve sex although this in itself could be seen as problematic and a 'symptom' of CSA. For some it was a lack of interest in sex which contributed to their coming to 'know' they had been sexually abused:

'Because I had no interest in sex and that to me was the reason why I was not interested in sex'. (Hazel)

'I thought well maybe that's what it is, I've been raped at some stage and just blocked it out or you know something has happened. Because I was very, I wouldn't let anybody really touch me at all'. (Pat)

5.24 Pat also recognised that she imposed contemporary attitudes onto her past without which her lack of interest or engagement in sexual activities might not be considered evidence of abuse: 
'Even when I had boyfriends I wouldn't go near them or... have a sexual relationship with anybody... that was quite normal'. (Pat)

Neither Hazel nor Pat had concrete memories of having been sexually abused and both used their sexual difficulties or lack of interest in sex to identify a history of CSA, and to explain their attitude and feelings to others. Hazel initially believed her memories of abuse, uncovered during hypnotherapy, because they made sense to her: she was having difficulty losing weight and disliked or was disinterested in sex, both of which were identified as symptoms of CSA. Hazel was happily married but did not enjoy sex and therefore, whilst she wanted to maintain her relationship with her partner, she wanted that relationship to be intimate without being sexual. She drew on contemporary narratives of CSA which enabled her to make sense of her lack of interest and avoid such a sexual relationship. However, she did at the same time recognise the unrealistic pressures on women to conform to the ideal of a healthy woman as sexually active and desirous, together with possibility that her CSA narrative might be a way to avoid sex. As she acknowledged, there were a number of reasons she might use to identify herself as a victim of CSA:

'I really do not know... Whether it's an excuse to... because my sexual life is horrendous and whether that's, I don't know. I don't know whether that's sort of an excuse if you like'. (Hazel)

5.26 Whilst she might, at least at times, have accepted the construction of the healthy adult woman as an active, sexual being, promoted in much of the CSA recovery literature, Hazel was also aware of the cultural pressures on women to conform to this ideal:

'Like you read in the newspapers some of it's four times a day and some four times a week and some it's four times a month or whatever. It's everybody to their own, there's too much pressure on us. Far too much pressure on us, you should do it when you feel like it not because you have to do it and that's how it should be'. (Hazel)

5.27 Hazel identified herself as a victim of CSA to avoid a sexual relationship with her partner but she recognised it was not the only explanation available to her, even if it was the most accessible or acceptable:

'It could be my hormones; it could be anything couldn't it?' (Hazel)

Whilst Hazel might have had an understanding partner who accepted her lack of sexual desire, she did feel she needed to justify this lack to him as well as to herself.

5.28 The narratives available to Hazel were not without problems. Although she believed women should only engage in sexual activity if and when they wanted to, this was contradicted by the idea of the healthy adult woman as sexually active and desirous. A narrative that drew on a hormonal/biological model along with a narrative that focussed on CSA both offered Hazel a way to negotiate a path which avoided sexual activity, whilst maintaining a happy relationship with her husband and a degree of intimacy that an unexplained (or justified) 'rejection' of sex might not have allowed her. Asexuality, as a positive identity, was not available to Hazel and it may be that for her a sexual abuse narrative offered the best 'guide to living' - a way to have an asexual relationship with her husband albeit one that required her to construct herself as damaged as a result of sexual abuse in childhood along with the possibility that her father had abused her. Her sexual abuse narrative was helpful, but it was one Hazel was not entirely happy with.

\section{Conclusion}

6.1 Contemporary self-help literature, including that aimed at victims of CSA, offers empowerment and a route to happiness and success. However, it does so in part by excluding the external factors that might constrain readers' possibilities and in part by identifying particular measures against which happiness and well-being are judged. The measures against which happiness and well-being are judged within the CSA recovery literature include sex and intimacy within which the healthy adult woman is constructed as sexually active, knowledgeable and desirous. This construction is in contrast to both the sexually innocent child (who should not yet be sexually active) and to the damaged (or not yet healed) and therefore childlike (because not yet sexually active and desirous or at least not in the right way) ongoing victim who is seen to be in need of sexual education and/or therapeutic intervention. So firmly established has the correlation between healthy adult womanhood and active sexuality become, that there is little room for the asexual woman unless she identifies as damaged and in need of healing - within which her lack of sexual desire can be seen as evidence of such damage.

Readers are offered a narrative framework within which to make sense of their lives and plan for the future that encourages them to conform to particular behaviours and see themselves as damaged in they fail (or fail to want) to conform. However, as Carol Tavris (1992) argues, we can be constrained as well as liberated by the stories we tell and whilst for some women these new stories of compulsory sex and intimacy might lead to 
new found sexual pleasure and desire, others might find themselves trapped within a narrative framework where someone else, such as a therapist, self-help writer or sexual partner, 'knows best' and where they are only free to narrate their own lives if that conforms to someone else's view of what kind of sexual being they should be. Whilst we are able to be the 'authors of our own plots', in drawing on narrative frameworks circulating in the twenty-first century women are drawing on frameworks that make it difficult to resist conforming to an idea of the sexually active, knowledgeable and desirous women - unless they construct themselves as damaged and in need of (sexual) education and healing.

\section{Acknowledgements}

I would like to thank the women who participated in the study on which this paper draws who shared their stories and gave generously of their time, and the Economic and Social Research Council (United Kingdom) for their financial support (R42200034452) for the research on which this paper draws.

\section{References}

BAKER, C. (2002) Female survivors of sexual abuse Hove: Brunner-Routledge.

BASS, E. and Davis, L. (1988) The courage to heal: a guide for women survivors of child sexual abuse(London: Cedar).

BASS E and L Davis (2008) (20th Anniversary ed). The courage to heal: A guide for women survivors of child sexual abuse New York: Harper Collins.

BAUMAN, Z (2001) The individualized society Cambridge: Polity.

BLUME, E. (1990) Secret survivors: uncovering incest and its effects in womenNew York: Ballantine Books.

BRAUN, V. and Clarke, V. (2006) Using thematic analysis in psychologyQualitative Research in Psychology, Vol.3 Issue 2, p. 77-101. [doi:10.1191/1478088706qp063oa]

BURGESS, R (1984) In the field: An introduction to field research London: Allen and Unwin. [doi:10.4324/9780203418161]

CARRIGAN, M (2011) There's more to life than sex? Difference and commonality within the asexual community Sexualities Vol.14 Issue 4, p. 462-478.

CONTRATTO, S. and Gutfreund, J.M. (1996) 'Introduction' in S. Contratto and M.J. Gutfreund (eds)A feminist clinician's guide to the memory debate New York: Harrington Park Press, p. 1-4. [doi:10.1300/j015v19n01_01]

COMFORT, A and Quilliam, S (2009) (Ultimate revised edition) The Joy of Sex : The timeless guide to love making, New York: Crown publishing.

DAVIS, M W (2003) The sex starved marriage London: Simon \& Schuster

DELVIN, D (1993) The Good Sex Guide: The Illustrated Guide to Enhance Your Love-makingLondon: Ebury Press.

DINSMORE, C (1991) From Surviving to Thriving: Incest, feminism and recoveryNew York: State University of New York Press.

EGAN, G (1982) The skilled helper Monterey CA: Brooks Cole.

FUREDI, F. (2004) Therapy culture London: Routledge.

GAVEY, N. (1993) Technologies and effects of heterosexual coercion. In S. Wilkinson and C. Kitzinger (eds) Heterosexuality: a feminism and psychology reader London: Sage, p. 93-119 
GAVEY, N. (2003) Writing the effects of sexual abuse. In P. and S. Warner (eds) New feminist stories of child sexual abuse: sexual scripts and dangerous dialogues London: Routledge, p. 187-209.

GAVEY, N (2005) Just Sex? The Cultural Scaffolding of Rape London and New York: Routledge.

GERGEN, M (1994) 'The social construction of personal histories: Gendered lives in popular autobiographies' in Sarbin, T and J Kitsuse (eds) Constructing the social London: Sage.

GUPTA, K and Cacchioni, T (2013) Sexual improvement as if your health depended on it: An analysis of contemporary sex manuals in Feminism and Psychology Vol. 23 Issue 4, p. 442-458.

HAAKEN, J. (1998) Pillar of salt: gender, memory and the perils of looking backLondon: Free Association Books.

HAAKEN, J. (1999) Heretical texts: the courage to heal and the incest survivor movement in S. Lamb (ed.) New versions of victims: feminists struggle with the concept New York: New York University Press.

HACKING, I. (1995) Rewriting the soul: multiple personality and the science of memoryPrinceton: Princeton University Press.

HARVEY, L and R Gill, (2011) The sex inspectors: Self-help, makeover and mediated sex in Ross, K (ed) Handbook on Gender, Sexualities and MediaOxford: Blackwell. [doi:10.1002/9781118114254.ch29]

HERMAN, J. (1992) Trauma and recovery: from domestic abuse to political terrorNew York: Basis Books.

KANE, C (2009) Sexually Shy: The Inhibited Woman's Guide to Good SexCleveland OH: Bukod Books.

KIRKWOOD, C (1993) Leaving abusive partners London: Sage.

JACKSON, S (1996) Lost childhood or sexualised girlhood? in S, Jackson (1999)Heterosexuality in question London: Sage p.135-148.

JACKSON, S (1998) 'Telling stories: Memory, narrative and experience in feminist research and theory' in Henwood, K, Griffin, C and A Phoenix (eds) Standpoints and differences: Essays in the practice of feminist psychology London: Sage.

JACKSON, S. and Scott, S. (2004) Sexual antinomies in late modernity.Sexualities, Vol. 7 Issue 2, p. 241-256. [doi:10.1177/1363460704042166]

KANE, C (2006) Good Sex: A Woman's Guide to Losing InhibitionNew Tradition Books.

KEESLING, B (2009) The Good Girl's Guide To Bad Girl SexLondon: Bantam Press.

KITZINGER, J. (1993) Sexual violence and compulsory heterosexuality in S. Wilkinson and C. Kitzinger (eds) Heterosexuality: a feminism and psychology reader London: Sage, p.291-238.

LAMB, S. (1999) Constructing the victim: popular images and lasting labels in S. Lamb (ed.)New versions of victims: feminists struggle with the concept New York: New York University Press.

LASCH, C (1979) The Culture of narcissism New York: Norton.

LAWLER, S (2002) 'Narrative in social research' in May, T (ed)Qualitative Research in ActionLondon: Sage.

LITVINOFF, S (2001) The Relate Guide To Sex In Loving RelationshipsLondon: Vermilion.

MALTZ, W. and Holman, B. (1986) Incest and sexuality: a guide to understanding and healing Lexington, MA: Lexington books.

MARTIN, A (2013) Fifty Shades of sex shop: Sexual fantasy for sale.Sexualities, Vol. 16, Issue 8, p.980-984. [doi:10.1177/1363460713508901]

O'DELL, L. (1997) Child sexual abuse and the academic construction of Symptomatologies. Feminism and psychology, Vol. 7 Issue 3, p.334-339. [doi:10.1177/0959353597073006]

O'DELL, L. (2003) The "harm" story in childhood sexual abuse: contested understandings, disputed knowledges in P. Reavey and S. Warner (eds) New feminist stories of child sexual abuse: sexual scripts and dangerous dialogues London: Routledge, p.131-147. 
PARKS, P. (1990) Rescuing the 'inner child': therapy for adults sexually abused as childrenLondon: Souvenir Press.

PENDERGRAST, M (1999) 'From Mesmer to memories: A historical, scientific look at the recovered memories controversy' in Taub, S (1999) Recovered memories of child sexual abuse Illinois: Charles C Thomas.

PLUMMER, K (1995) Telling sexual stories London: Routledge. [doi:10.4324/9780203425268]

PLUMMER, K (2001) Documents of life 2: An invitation to a critical humanismLondon: Sage.

PRZYBYLO, E (2011) Crisis and safety: The asexual in sexusociety inSexualities Vol. 14 Issue 4, p. 444-461.

REAVEY, P. and Warner, S. (2001) Curing women: child sexual abuse, therapy and the construction of femininity. International Journal of Critical Psychology, Special issue on Sex and Sexualities Vol.3 p. 4971.

REAVEY, P. (2003) When past meets present to produce a sexual 'other': examining professional and everyday narratives of child sexual abuse and sexuality in P. Reavey and S. Warner (eds) New feminist stories of child sexual abuse: sexual scripts and dangerous dialogues London: Routledge, p. 148-166.

[doi:10.4324/9780203361573]

ROSE, N (1989) (2nd edition) Governing the soul London: Free association books.

SCHERRER K (2008) Coming to an Asexual identity: Negotiating identity, negotiating desireSexualities 11(5) p. 621-641. [doi:10.1177/1363460708094269]

SENNETT, R (1993) The fall of public man(New edition) London: Faber and Faber.

SHOWALTER, E. (1997) Hystories: hysterical epidemics and modern culture London: Picador.

SIMONDS, W (1996) 'All consuming selves: self-help literature and women's identities' in Grodin, D and T Lindlof (eds) ' Constructing the self in a mediated worldLondon: Sage. [doi:10.4135/9781483327488.n2]

SPARX, A (2011) The Naughtiest Sex Guide (with Bonus Erotica) EBook self published.

SPURR, P (2002) Sinful Sex: The Uninhibited Guide to Erotic PleasureLondon: Robson Books Ltd.

SPURR, P (2007) Fabulous Foreplay: The Sex Doctor's Guide to Teasing and Pleasing Your LoverLondon: JR Books Ltd.

SPURR, P (2008) Sizzling Sex: The Sex Doctor's 250 Hottest Tips, Tricks and TechniquesLondon: JR Books Ltd.

TAVRIS, C (1992) Mismeasure of woman: Why women are not the better sex, the inferior sex, or the opposite sex. New York: Touchstone Books.

WHYTE, W (1982) 'Interviewing in the field' in Burgess, R (ed)Field research: a source book and field manual London: Allen and Unwin.

WARNER, S (1996) 'Constructing femininity: models of child sexual abuse and the production of "woman"' in E Burman, P Alldred, C Bewley et al Challenging women: psychology's exclusions, feminist possibilities Buckingham: Open University Press.

WOODIWISS, J (2007) 'Politics, responsibility and childhood sexual abuse',Sociological Research Online Vol. 12, Issue 2, http://www.socresonline.org.uk/12/2/woodiwiss.html.

WOODIWISS, J (2009) Contesting stories of childhood sexual abuse, Basingstoke: Palgrave Macmillan. [doi:10.1057/9780230245150]

WOODIWISS, J (2010) 'Alternative memories of childhood sexual abuse' in Haaken, J and Reavey, P (eds) Memory Matters: Contexts for understanding sexual abuse recollections, London: Routledge.

WOODIWISS, J (2013) 'Bridging the gap between past and present: childhood sexual abuse, recovery and the contradictory self', Women's Studies International Forum, 38. [doi:10.1016/j.wsif.2013.03.007]

WOODIWISS, J (2014) 'Beyond a single story - the importance of separating 'harm' from 'wrongfulness' and 
'sexual innocence' from 'childhood' in contemporary narratives of childhood sexual abuse', Sexualities Vol.17 Issue 1-2, p. 139-158. 